\title{
Hydrogen gas sensing using palladium-coated microdisk microresonators
}

\author{
Mustafa Eryürek ${ }^{a}$ and Yasin Karadag ${ }^{b}$ and Nevin Taşaltın ${ }^{c}$ \\ and Necmettin Kılınç ${ }^{d}$ and Alper Kiraz ${ }^{e, f}$ \\ ${ }^{a}$ Department of Physics, Koç University, Rumelifeneri Yolu, 34450 Sarıyer, İstanbul, Turkey; \\ ${ }^{b}$ Department of Physics, Marmara University, 34722 Göztepe, İstanbul, Turkey; \\ ${ }^{c}$ TUBITAK MRC Materials Institute, Sensor Materials-Photonic Technologies Lab., 41470 \\ Gebze, Kocaeli, Turkey; \\ ${ }^{d}$ Mechatronics Engineering Department, Niğde University, 51245 Niğde, Turkey; \\ ${ }_{f}^{e}$ Department of Physics, Koç University, Rumelifeneri Yolu, 34450 Sarıyer, İstanbul, Turkey; \\ Koç University TÜPRAŞ Energy Center (KÜTEM), Koç University, Rumelifeneri Yolu, 34450 \\ Sarıyer, İstanbul, Turkey;
}

\begin{abstract}
An SU-8 polymer microdisk resonator coated with a palladium (Pd) layer and coupled to a single-mode optical waveguide is used to as a hydrogen $\left(\mathrm{H}_{2}\right)$ gas sensor. In the presence of $\mathrm{H}_{2}$, a red shift is observed in the spectral positions of the microdisk whispering gallery modes (WGMs) due to the expansion in the Pd lattice. $\mathrm{H}_{2}$ concentrations below the flammable limit (4\%) down to $0.3 \%$ could be detected in nitrogen atmosphere at room temperature. For $\mathrm{H}_{2}$ concentrations between $0.3-1 \%$, WGM spectral positions shifted linearly with $\mathrm{H}_{2}$ concentration at a rate of $32 \mathrm{pm} / \% \mathrm{H}_{2}$. Average response time of the devices was measured to be $50 \mathrm{~s}$ for $1 \% \mathrm{H}_{2}$. The proposed device concept can also be used to detect different chemical gases by using appropriate sensing layers.
\end{abstract}

Keywords: Microdisk resonator, SU-8 polymer, hydrogen sensing, waveguide coupling

\section{INTRODUCTION}

Hydrogen $\left(\mathrm{H}_{2}\right)$ attracts a lot of attention as an energy source because to its high energy conversion efficiency, nontoxic side products, and sustainable nature, ${ }^{1,2}$ In addition to that, $\mathrm{H}_{2}$ is widely employed in clinical, industrial, and environmental reservation applications. Storage and sensing of $\mathrm{H}_{2}$ are the main challenge due to its low flammable limit (4\%) and small molecular volume. To date, $\mathrm{H}_{2}$ sensors have been demonstrated using different measurement methods such as thermal, ${ }^{3}$ electrical, ${ }^{4}$ mechanical,${ }^{5}$ acoustic ${ }^{6}$ or optical. ${ }^{7}$ Among these, optical sensing techniques are generally convenient for achieving reversible sensing with low cost and compact devices. The first optical $\mathrm{H}_{2}$ sensor relied on the interferometric detection of the length of a palladium (Pd) - coated optical fiber. ${ }^{8}$ This work was followed by other optical $\mathrm{H}_{2}$ sensor demonstrations including those employing reflection spectroscopy ${ }^{9}$ reflectivity ${ }^{10}$ or surface plasmon resonance phenomenon. ${ }^{11}$

In this paper, we report a novel optical sensor of $\mathrm{H}_{2}$ gas that employs a polymer microdisk microresonator coated with a palladium $(\mathrm{Pd})$ sensing layer and optically coupled to a single-mode polymer waveguide. Microdisk cavities host high quality optical resonances called whispering gallery modes (WGMs) whose spectral positions are very sensitive reporters of the microresonator size and refractive index. ${ }^{12}$ Our sensor detects the $\mathrm{H}_{2}$ gas via monitoring the spectral position of the WGMs that changes due to the strain induced in the microresonator as a result of expansion in the Pd sensing layer upon the formation of palladium hydride. To determine the WGM positions, we employ a tunable laser coupled into the polymer waveguide. We report $\mathrm{H}_{2}$ detection below the flammable limit down to $0.3 \%$, with a linear response of the sensor in the $\mathrm{H}_{2}$ concentration range between $0.31 \%$ and a typical response time around $50 \mathrm{~s}$ for $1 \% \mathrm{H}_{2}$.

Further author information: (Send correspondence to A.K.)

A.K.: E-mail: akiraz@ku.edu.tr, Telephone: +902123381701

Laser Resonators, Microresonators, and Beam Control XVII, edited by Alexis V. Kudryashov, Alan H. Paxton, Vladimir S. Ilchenko, Lutz Aschke, Kunihiko Washio, Proc. of SPIE Vol. 9343, 93430J - (c) 2015 SPIE CCC code: $0277-786 X / 15 / \$ 18 \cdot$ doi: $10.1117 / 12.2078244$ 
Up to now, elastic nature of polymer microring or microdisk microresonators has been exploited in numerous demonstrations such as strain sensing, ${ }^{13}$ ultrasonic detection for photoacoustic microscopy, ${ }^{14}$ and optomechanically tunable lasing. ${ }^{15}$ Despite these, $\mathrm{H}_{2}$ gas sensing using a polymer microring or microdisk microresonator has not been demonstrated yet. Solid silicon-on-insulator (SOI) ring resonators have been previously used for $\mathrm{H}_{2}$ gas sensing. ${ }^{16}$ In these experiments, $\mathrm{H}_{2}$ was detected by monitoring the spectral change in WGMs caused by the local temperature increase resulting from the catalytic combustion of $\mathrm{H}_{2}$. However, this approach did not allow measurement of $\mathrm{H}_{2}$ concentrations lower than $0.7 \%$. Vertical cavity lasers ${ }^{17}$ were also used in microresonator-based $\mathrm{H}_{2}$ gas sensing demonstrations. Here, $\mathrm{H}_{2}$ gas sensing relied on the change of the complex refractive index of a $\mathrm{Pd}$ layer, leading to a spectral shift of the lasing wavelength. Compared to these previous demonstrations, our sensor combines easy fabrication together with the detection of relatively low $\mathrm{H}_{2}$ concentrations $(0.3 \%)$.

\section{EXPERIMENTAL}

\subsection{Microfabrication}

The sensor devices are fabricated using a two-step photolithography process (Fig. 1a). Si-wafer with $5 \mu$ m-thick oxide layer is used as the substrate to have the substrate refractive index lower than that of SU-8. In the first step, SU-8 microresonator and waveguide structures are fabricated. The thickness of this layer is measured as $1.2 \mu \mathrm{m}$. Then in the second step, thin Pd disks $(220 \mathrm{~nm})$ are coated concentrically on the microresonators using $\mathrm{RF}$ plasma sputtering. The outer diameters of the Pd disks are designed to be less than the outer diameters of the microresonators to avoid loss of optical WGMs propagating at the edges of the microdisks (Fig. 1b).

\subsection{Optical measurements}

Optical measurements are carried out by detecting a tunable laser light (wavelength range 1500-1620 nm) coupled to the SU-8 waveguide using butt-coupling method $^{18}$ (Fig. 1c). As the wavelength of the laser is changed, optical WGMs are observed at resonance wavelengths (i.e. wavelengths satisfying the resonance condition of the microresonator.) $2.46 \mathrm{~nm}$ FSR (separation between consecutive WGMs) is observed with quality factors around 1000. Sensor devices are put into a gas chamber in which $H_{2}$ and $N_{2}$ gas concentrations can be controlled with gas flow controllers. Before the transmission spectrum of the microresonator is measured, the gas chamber is flooded with $\mathrm{N}_{2}$ for 30 minutes to rule out any possible effects of humidity. As the transmission spectrum is being measured, $\mathrm{H}_{2}$ is released to the chamber at the desired concentrations using the gas flow controllers (Fig. 1d).

\section{RESULTS AND DISCUSSION}

The sensing mechanism of the polymer optical microresonator-based sensor relies on the volume expansion of the $\mathrm{Pd}$-coating in the presence of $\mathrm{H}_{2}$. When the $\mathrm{H}_{2}$ gas is introduced into the gas chamber, $\mathrm{H}_{2}$ molecules are adsorbed in the $\mathrm{Pd}$ and they disintegrate into hydrogen ions, forming palladium hydride, $\mathrm{PdH}_{\mathrm{x}}$. Since the $P d H_{x}$ formation causes an increase in the lattice constant of $\mathrm{Pd}^{19}$ the volume of the coating is increased under $\mathrm{H}_{2}$ exposure. This volume expansion is transferred to the polymer microresonator. Since the WGM resonances are highly sensitive to the size of the microresonator, a red-shift is observed for the WGMs in the presence of $\mathrm{H}_{2}$. The amount of red-shift depends on the $\mathrm{H}_{2}$ concentration in the environment.

Fig.s 2a-b show the sensing responses recorded from the uncoated and Pd-coated microresonators, respectively. For the uncoated device, red spectral shift of about $14 \mathrm{pm}$ is observed for $10 \% \mathrm{H}_{2}$ concentration, as seen in Fig. 2a. This corresponds to a very low $\mathrm{H}_{2}$ detection that can be mainly attributed to the refractive index change in SU-8 as a result of $\mathrm{H}_{2}$ adsorption. ${ }^{20}$ However, for the case of the Pd-coated device, 29 pm red spectral shift is observed for $1 \% \mathrm{H}_{2}$ concentration. Changes of the refractive indices of SU-8 and $\mathrm{Pd}$ are other potential sources for the observed red spectral shift. We conclude these contributions are negligible for two reasons: (i) Control experiments shown in Fig. 2a reveal much smaller $\mathrm{H}_{2}$ detection sensitivity due to the refractive index change of SU-8, and (ii) in our sensor devices Pd-layer does not cover the region near the rim of the microdisk where WGMs are residing. We also note that a decrease in sensitivity of the devices was typically observed upon 
(a)
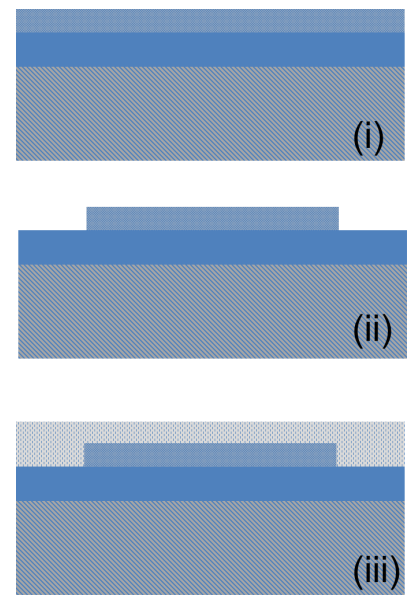

$\mathrm{SU}-8 \quad \mathrm{SiO}_{2}$
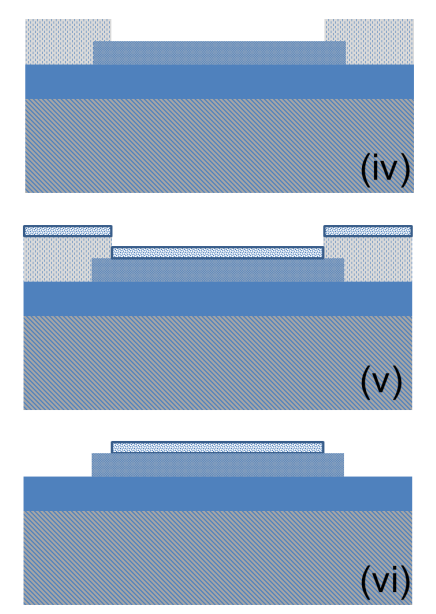

Si Lift-off photoresist (b)

(d)

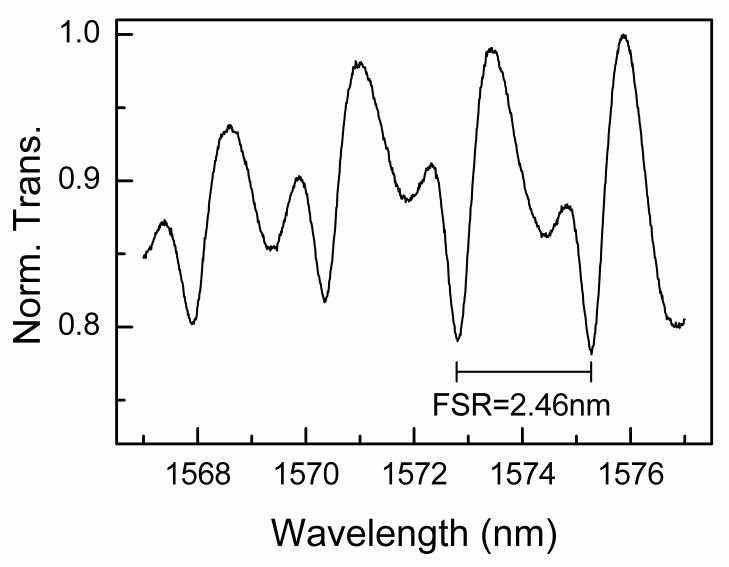

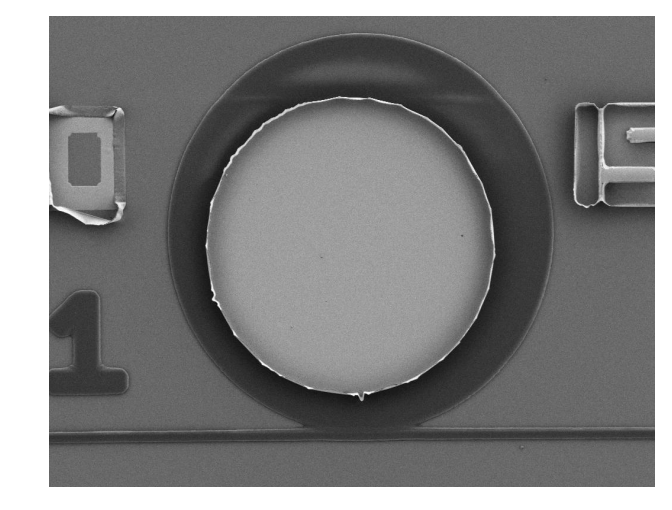

(c)

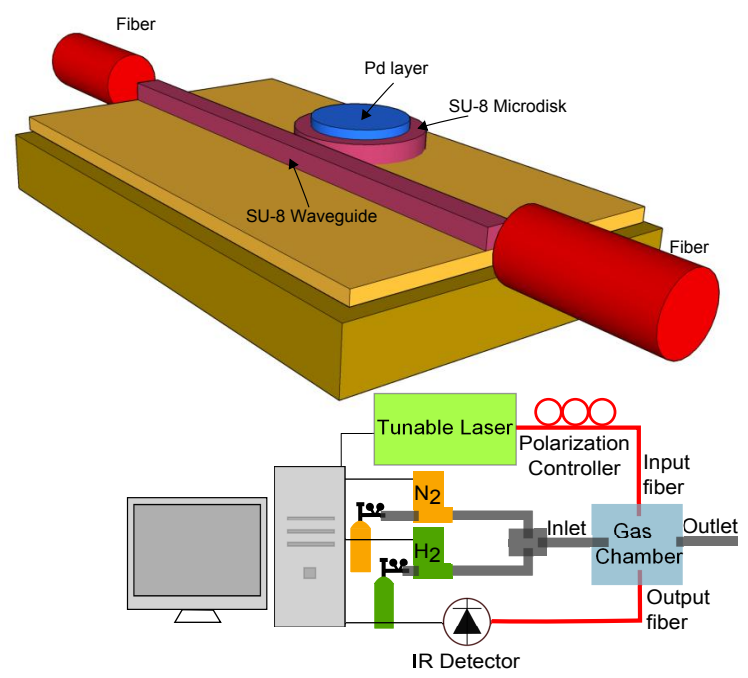

Figure 1. a) Cross-sectional schematic views showing the microfabrication steps of the sensor device. Thicknesses: Pd $220 \mathrm{~nm}, \mathrm{SU}-8-1200 \mathrm{~nm}, \mathrm{SiO}_{2}-5 \mu \mathrm{m}, \mathrm{Si}-500 \mu \mathrm{m}$. b) SEM image of a $200 \mu \mathrm{m}$-diameter Pd-coated SU-8 microresonator with SU-8 waveguide. c) Schematic representation of the sample and the experimental setup. d) Transmission spectrum obtained from a Pd-microresonator device. FSR is calculated as $2.46 \mathrm{~nm}$. 

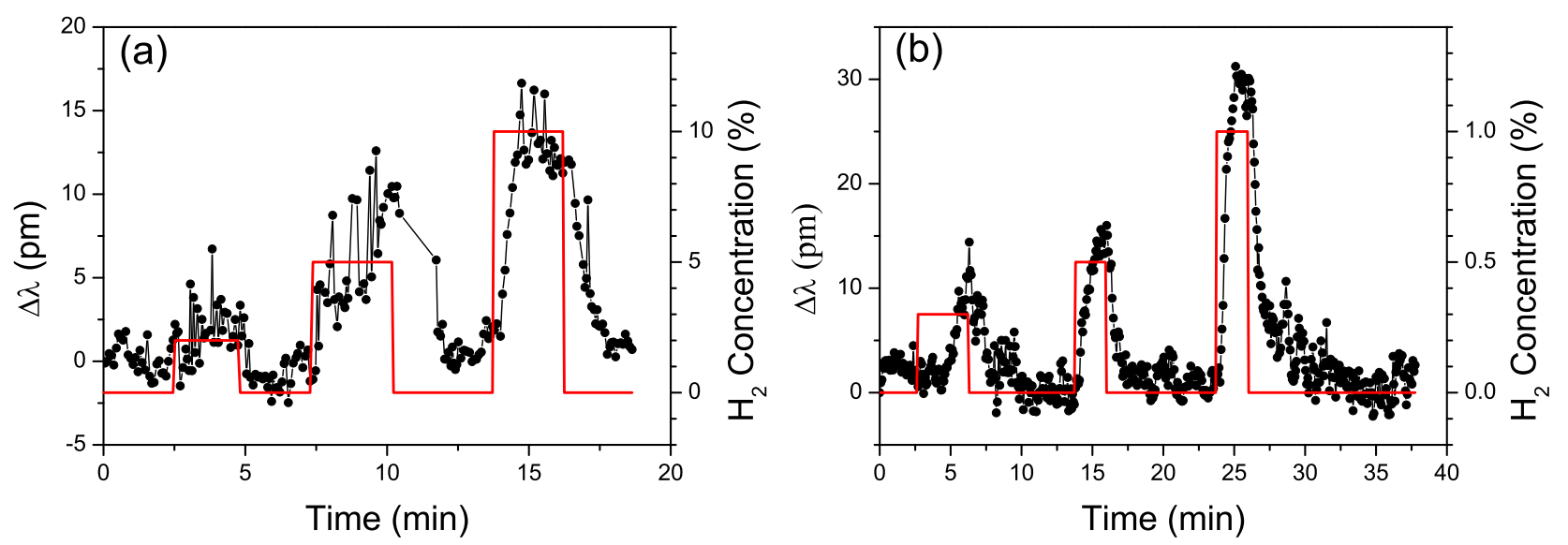

Figure 2. WGM resonance shifts obtained from (a) uncoated and (b) Pd-coated microresonators. The red lines show the $\mathrm{H}_{2}$ concentration in the environment as a function of time. $10 \% \mathrm{H}_{2}$ causes about 15 pm resonance shift for uncoated microresonator whereas about $30 \mathrm{pm}$ resonance shift is observed for only $1 \% \mathrm{H}_{2}$ for Pd-coated microresonator.
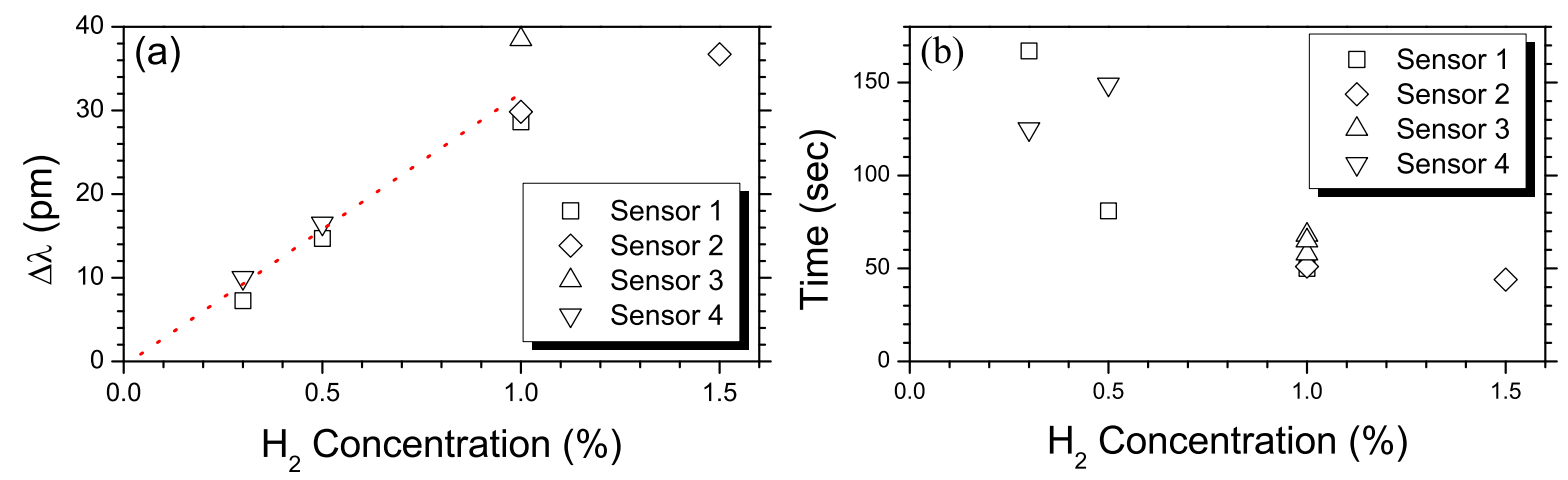

Figure 3. (a) $\mathrm{H}_{2}$ concentration vs. resonance shift graph for different sensor devices. The red line shows the linear fit for $\mathrm{H}_{2}$ concentrations up to $1 \%$. (b) Response time vs. resonance shift graph for different sensor devices.

repeated cycles of $\mathrm{H}_{2}$ exposure. This was attributed to the incomplete removal of hydrogen from the Pd lattice ${ }^{21}$ and partial breaking of bonds between the Pd and SU-8 surfaces. For a given sensor device, we always used data recorded during the first set of experiments in calculating the sensitivity values reported in this paper.

Fig.s 3a-b show the resonance shifts and response times of different sensor devices as a function of $\mathrm{H}_{2}$ concentration. The linear fit has the slope of $32 \mathrm{pm} / \% \mathrm{H}_{2}$. Beyond $1 \% \mathrm{H}_{2}$ concentration, saturation is observed in the sensor response. This can be explained by the irreversible beta-phase formation in the $\mathrm{PdH}_{x}$ for $x>1.5 \%{ }^{19}$

For our sensor devices, response and recovery times were determined by analyzing the recorded time traces of the WGM spectral shifts shown in Fig. 2b. The response and recovery times correspond to the times required for the spectral shift to change by $90 \%$ of the total spectral change observed upon initiating or stopping the $\mathrm{H}_{2}$ flow in the chamber, respectively. For the experimental data shown in Fig. 2b, the response and recovery times were calculated as $167,81,50 \mathrm{~s}$ and $55,73,163 \mathrm{~s}$ for $0.3,0.5,1 \% \mathrm{H}_{2}$, respectively (see also Fig. 3b for the summary of the response dynamics of multiple devices). As expected, the response time decreases with increasing $\mathrm{H}_{2}$ concentration. This behavior can be explained by the concentration-dependent surface adsorption of $\mathrm{H}_{2}$ which represents the rate-limiting step in the $\mathrm{PdH}_{x}$ formation. ${ }^{22}$ Similar trends were observed in the previously reported optical $\mathrm{H}_{2}$ sensors. ${ }^{11,22}$ The increase of the sensor recovery time with increasing $\mathrm{H}_{2}$ concentration can be attributed to the delayed removal of hydrogen which has to undergo spatially constrained diffusion out of the Pd lattice. 


\section{CONCLUSIONS}

In conclusion, using sensors based on optical signal readout, we have demonstrated detection of $\mathrm{H}_{2}$ at room temperature with the lower detection limit of $0.3 \%$ and the response time of $50 \mathrm{~s}$ for $1 \% \mathrm{H}_{2}$. Presented polymer microresonator sensors are low-cost, compact, and easy to fabricate. As compared to other state-of-the-art optical $\mathrm{H}_{2}$ sensors, they hold a special promise for detecting extremely low $\mathrm{H}_{2}$ concentrations. This can be achieved by increasing the Q-factors of the WGMs with higher resolution lithography techniques, having a better control over the environmental conditions in the gas sample chamber, and studying microdisks possessing undercut regions. With modified sensing coatings, this optical sensing platform is also suitable for detecting different gas species.

\section{ACKNOWLEDGMENTS}

We acknowledge financial support from TÜBİTAK (grant no. 110T803).

\section{REFERENCES}

[1] Christofides, C. and Mandelis, A., "Solid-state sensors for trace hydrogen gas detection," J. Appl. Phys. 68(6), R1-R30 (1990).

[2] Hübert, T., Boon-Brett, L., Black, G., and Banach, U., "Hydrogen sensors a review," Sensors and Actuators B 157, 329-352 (2011).

[3] Lee, E.-B., Swang, I.-S., Cha, J.-H., Lee, H.-J., Lee, W.-B., Pak, J. J., Lee, J.-H., and Ju, B.-K., "Micromachined catalytic combustible hydrogen gas sensor," Sensors and Actuators B 153, 392-397 (2011).

[4] Favier, F., Walter, E. C., Zach, M. P., Benter, T., and Penner, R. M., "Hydrogen sensors and switches from electrodeposited palladium mesowire arrays," Science 293, 2227-2231 (2001).

[5] Chou, Y.-I., Chiang, H.-C., and Wang, C. C., "Study on Pd functionalization of microcantilever for hydrogen detection promotion," Sensors and Actuators B 129, 72-78 (2008).

[6] Dong, S., Bai, F., Li, J., and Viehland, D., "Sound-resonance hydrogen sensor," Applied Physics Letters 82(25), 4590-4592 (2003).

[7] Silva, S. F., Coelho, L., Frazao, O., Santos, J. L., and Malcata, F. X., "A review of palladium-based fiber-optic sensors for molecular hydrogen detection," IEEE Sensors Journal 12(1), 93-102 (2012).

[8] Butler, M. A., "Optical fiber hydrogen sensor," Applied Physics Letters 45(10), 1007-1009 (1984).

[9] Maciak, E. and Opilski, Z., "Transition metal oxides covered Pd film for optical $\mathrm{H}_{2}$ gas detection," Thin Solid Films 515, 8351-8355 (2007).

[10] Bévenot, X., Trouillet, A., Veillas, C., Gagnaire, H., and Clément, M., "Hydrogen leak detection using an optical fiber sensor for aerospace applications," Sensors and Actuators B 67, 57-67 (2000).

[11] Bévenot, X., Trouillet, A., Veillas, C., Gagnaire, H., and Clément, M., "Surface plasmon resonance hydrogen sensor using an optical fibre," Measurement Science and Technology 13, 118-124 (2002).

[12] Jonáš, A., Karadag, Y., Mestre, M., and Kiraz, A., "Probing of ultrahigh optical q-factors of individual liquid microdroplets on superhydrophobic surfaces using tapered optical fiber waveguides," J. Opt. Soc. Am. B 29, 3240-3247 (2012).

[13] Bhola, B., Song, H.-C., Tazawa, H., and Steier, W. H., "Polymer microresonator strain sensors," IEEE Photonics Technology Letters 17(4), 867-869 (2005).

[14] Li, H., Dong, B., Zhang, Z., Zhang, H. F., and Sun, C., "A transparent broadband ultrasonic detector based on an optical micro-ring resonator for photoacoustic microscopy," Scientific Reports 4, 4496 (2014).

[15] Flatae, A. M., Buresi, M., Zeng, H., Nocentini, S., Wiegele, S., Wiersma, D., and Kalt, H., "Optomechanically tunable polymeric microlasers," in [CLEO], (2014).

[16] Yebo, N. A., Taillaert, D., Roels, J., Lahem, D., Debliquy, M., Thourhout, D. V., and Baets, R., "Siliconon-insulator (soi) ring resonator-based integrated optical hydrogen sensor," IEEE Photonics Technology Letters 21(14), 960-962 (2009).

[17] Griffin, B. G., Arbabi, A., Kasten, A. M., Choquette, K. D., and Goddard, L. L., "Hydrogen detection using a functionalized photonic crystal vertical cavity laser," IEEE Journal of Quantum Electronics 48(2), 160-168 (2012). 
[18] Bellini, B., dAlessandro, A., and Beccherelli, R., "A method for butt-coupling optical fibres to liquid crystal planar waveguides," Optical Materials 29, 1019-1022 (2007).

[19] Noh, J.-S., Lee, J. M., and Lee, W., "Low-dimensional palladium nanostructures for fast and reliable hydrogen gas detection," Sensors 11, 825-851 (2011).

[20] Sato, S., Ose, T., Miyata, S., Kanehashi, S., Ito, H., Matsumoto, S., Iwai, Y., Matsumoto, H., and Nagai, K., "Relationship between the gas transport properties and the refractive index in high-free-volume fluorinecontaining polyimide membranes," Journal of Applied Polymer Science 121, 2794-2803 (2011).

[21] Avila, J. I., Matelon, R. J., Trabol, R., Favre, M., Lederman, D., Volkmann, U. G., and Cabrera, A. L., "Optical properties of pd thin films exposed to hydrogen studied by transmittance and reflectance spectroscopy," Journal of Applied Physics 107, 023504 (2010).

[22] Zhao, Z., Sevryugina, Y., Carpenter, M. A., Welch, D., and Xia, H., "All-optical hydrogen-sensing materials based on tailored palladium alloy thin films," Analytical Chemistry 76, 6321-6326 (2004). 